\title{
Flame retardant effect of lignin/carbon nanotubes/ potassium carbonate composite coatings on cotton roving
}

\author{
Damian Lukawski (D) Wojciech Grześkowiak • Agnieszka Lekawa-Raus • \\ Małgorzata Widelicka · Filip Lisiecki $\cdot$ Alina Dudkowiak
}

Received: 27 November 2019/ Accepted: 29 May 2020/Published online: 6 June 2020

(C) The Author(s) 2020

\begin{abstract}
A new composite flame retardant coating for cotton roving has been investigated. The proposed coating comprises natural lignin, pure carbon allotrope carbon nanotubes (CNTs) and non-toxic potassium carbonate $\left(\mathrm{K}_{2} \mathrm{CO}_{3}\right)$. The series of complementary experiments, including thermogravimetric analysis, vertical burning in fire tube, limiting oxygen index (LOI) measurement and combustion in mass loss calorimeter enabled the formulation of an optimum composition including aqueous suspension with $1 \mathrm{wt} \%$ of CNTs, $1 \mathrm{wt} \%$ lignin (L) as well as $1 \mathrm{wt} \%$ of $\mathrm{K}_{2} \mathrm{CO}_{3}$. Applying $\mathrm{L} / \mathrm{CNT} / \mathrm{K}_{2} \mathrm{CO}_{3}$ on cotton roving
\end{abstract}

Electronic supplementary material The online version of this article (https://doi.org/10.1007/s10570-020-03270-y) contains supplementary material, which is available to authorized users.

D. Łukawski $(\bowtie) \cdot$ A. Dudkowiak

Faculty of Technical Physics, Poznan University of

Technology, Piotrowo 3, 60-965 Poznan, Poland

e-mail: damian.lukawski@put.poznan.pl

\section{W. Grześkowiak}

Faculty of Wood Technology, Poznan University of Life Sciences, 60-628 Poznan, Poland

\author{
A. Lekawa-Raus \\ Faculty of Mechatronics, Warsaw University of \\ Technology, 02-525 Warsaw, Poland \\ M. Widelicka $\cdot$ F. Lisiecki \\ Institute of Molecular Physics, Polish Academy of \\ Sciences, 60-179 Poznan, Poland
}

increased LOI from 17.1 to $38.5 \%$, decreased final mass loss and temperature during vertical burning from 100 to $78 \%$ and 457 to $190{ }^{\circ} \mathrm{C}$, respectively. Moreover, peak heat release rate and total heat released dropped from 97.5 to $70.4 \mathrm{~kW} / \mathrm{m}^{2}$ and from 4.2 to $1.6 \mathrm{MJ} / \mathrm{m}^{2}$, respectively . The above experiments supported by scanning electron microscopy and Raman spectroscopy allowed also the explanation of the complementary mechanisms responsible for the overall fire retardant effect.

Keywords Cotton - Carbon nanotubes · Coating · Flame retardant $\cdot$ Lignin $\cdot$ Potassium carbonate

\section{Introduction}

Cellulose, the main compound of cotton fibers, is the most abundant biopolymer largely used for environmental protection, water treatment, biomedical applications, food packaging, textile industry, civil engineering and others (Vroman and Tighzert 2009).

Cellulose is composed of two anhydroglucose rings $\left(\mathrm{C}_{6} \mathrm{H}_{10} \mathrm{O}_{5}\right)_{\mathrm{n}}$ with linear homopolymer of glucopyranose residues connected by $\beta$-1,4-glycosidic bond. The combustion of cellulose begins with its pyrolysis (Shen et al. 2011). At low temperature the initial process is delayed, which leads to a reduction in the degree of polymerization and formation of active cellulose (Shen and Gu 2009). High temperature 
pyrolysis of cellulose is developed through two competitive degradation reactions: the first one is the formation of char and gas, and second one is leads mostly to formation of tars. In the presence of oxygen the volatile gases, resulting from pyrolysis, ignite starting the rapid combustion (White and Nordheim 1992).

Due to high flammability of cotton fibers, they should be coated with fire retardants for a variety of uses such as clothing, furniture, thermal insulation and others. Fire retardants consist of inorganic and organic compounds (mostly organohalogen, boron, organophosphorus) (Mohamed and Hassabo 2015). The mode of action of most of these compounds is the lowering of the decomposition temperature and stimulating formation of a char layer on the surface (Gaan and Sun 2009; Bocchini et al. 2010). A particularly important feature is the production of char layer during polymer combustion. Charred layer makes a thermal insulation, slowing down the thermal decomposition of the material and a barrier to reduce the emission of flammable decomposition products into the flames (White and Nordheim 1992; Kandola et al. 1996; Grześkowiak 2017).

Despite high fire suppressing action of organohalogens, their use is limited because of their toxicity (Rahman et al. 2001; Lyche et al. 2015). Borax, boric acid and diammonium phosphate are cheap, water soluble and well performing fire retardants (Lyons 1976). However, they may show a tendency to crystallize and are not durable as they can be removed on washing. In order to make the fire retardant cellulose resistant to washing, cellulose fibers need to be chemically modified by e.g. esterification with phosphates, crosslinking of cellulose fibers by fire retardant, introduction of chemical substituent on cellulose or in situ polymerization. Unfortunately, many of durable fire retardants contain toxic organohalogens (Mohamed and Hassabo 2015). Therefore new fire retardant compositions are still searched for.

The intensive research in the area of nanomaterials taking place for over the last 30 years has inspired us to check the possibility of employing them as flame retardants. One of the nanomaterials found particularly promising in this respect are carbon nanotubes (CNTs) (Kashiwagi et al. 2005a). CNTs are pure carbon allotropes belonging to the graphite family. They are already produced on a large scale and are available on the market at low cost. Their flame retardant properties stem from their thermal stability and high thermal conductivity (Kashiwagi et al. 2005a). According to the studies of Kashiwagi et al. (Kashiwagi et al. 2005b; Cipiriano et al. 2007) they may be used as flame retardants of polymers. CNTs dispersed in polymer matrix decreased the two key flammability parameters: mass loss rate (MLR, speed of material decay due to burning) and peak heat release rate (PHRR, which quantifies the amount of heat released during burning).

Fire retardant effect found in polymers enriched with CNTs inspired the development of CNT wrapped cotton fabrics (Gonçalves et al. 2012; Chen et al. 2016; Ding et al. 2016). Unfortunately, the first trial in this area based on incorporation of functionalized multiwall carbon nanotubes (MWCNTs) into cotton fabrics did not decrease the flammability of the latter (Gonçalves et al. 2012). Therefore, further studies were performed, which focused on coating of the cotton fabrics with CNT-enhanced polymer layers (Chen et al. 2016; Ding et al. 2016). A multifunctional coating made of polyhexamethylene guanidine phosphate (PHMGP) and potassium alginate functionalized carbon nanotubes (PA-CNTs) eliminated afterglow effect during vertical burning (Chen et al. 2016), whilst PHMGP with fluorescent whitening agents and CNTs showed a decrease in total heat released (THR) and PHRR (Ding et al. 2016). Both these experiments brought about promising results, but only simple vertical and burning tests were performed. Additionally, exposure to PHMG bears a risk of lung diseases (Lee and Yu 2017).

In our previous studies we showed that carbon nanomaterials, including CNTs may be successfully composited with wood chips (Lukawski et al. 2019) showing slight flame retardant effect and can create superhydrophobic coatings of wood and cotton (Łukawski et al. 2018a, b). In the study presented, we propose the use of CNT/lignin based coatings on cotton as flame retardant agents. Lignin is the second most abundant bio-polymer and it is a waste from paper production. In our study, lignin enables dispersion of CNTs in water without their chemical (bondbreaking) functionalization (Milczarek and Nowicki 2013). Additionally, lignin alone shows some fire retardant properties (Reti et al. 2008; Song et al. 2011; Vänskä et al. 2016). So as to complement the flame retardant action, a non-toxic (used also as cooking 
additive) potassium carbonate $\left(\mathrm{K}_{2} \mathrm{CO}_{3}\right)$ (Grzeskowiak 2012), was added to aqueous $\mathrm{CNT} /$ lignin dispersion.

\section{Experimental}

Cotton/lignin preparation

Degreased cotton roving $\left(\right.$ BRAND $^{\circledR}$ cotton roving of linear density of approx. $1.3 \mathrm{~g}$ per $1 \mathrm{~m}$ ) used in all experiments was purchased from Sigma Aldrich. Kraft lignin (alkali, low sulfonate content, $\mathrm{M}_{\mathrm{w}} \approx 10,000$, Sigma Aldrich) powder was dissolved in deionized water $(1 \mathrm{wt} \%)$ to form base lignin solution. Aqueous lignin suspension was also enriched with $1 \mathrm{wt} \%$ of $\mathrm{K}_{2} \mathrm{CO}_{3}(99 \%$, AltaiirChimicaSpA). This suspension is further referred to as $\mathrm{L} / \mathrm{K}_{2} \mathrm{CO}_{3}$ solution. Then CNTs (MWCNTs Nanocyl NC7000, average diameter $9 \mathrm{~nm}$, average length $1.5 \mu \mathrm{m}$ ) was added to the aqueous lignin solution with $0.05 \mathrm{wt} \%, 0.3 \mathrm{wt} \%, 1 \mathrm{wt} \%$ concentration, respectively and suspended by ultrasonic homogenization using Hielsher UP400St sonotrode. These will be further referred to as L/CNT (0.05), L/CNT (0.3) and L/CNT (1) respectively. Similarly, $1 \mathrm{wt} \%$ concentration of CNTs was added to $\mathrm{L} / \mathrm{K}_{2} \mathrm{CO}_{3}$ solution to form $\mathrm{L} / \mathrm{K}_{2} \mathrm{CO}_{3} / \mathrm{CNT}$ solution.

The cotton roving samples were dried in $80{ }^{\circ} \mathrm{C}$ in air for $24 \mathrm{~h}$ and then weighed. Next, the suspensions were deposited cotton roving samples (Table 1) by dip coating. Wet samples were dried at $80{ }^{\circ} \mathrm{C}$ in air for $24 \mathrm{~h}$ and weighed. The weight gain (WG, wt $\%$ ) of the treated cotton samples of CNT, lignin (L) and potassium carbonate coating in cotton was calculated according to Eq. 1 and presented in supplementary materials (Table S1, S2 and S3).

$W G(\%)=\frac{m_{f}-m_{i}}{m_{i}} * 100 \%$ $\mathrm{m}_{\mathrm{i}}$-initial mass of dry cotton, $m_{f}$-final mass saturated cotton.

\section{Initial characterization}

The scanning electron microscopy (SEM) images were taken by an FEI Nova NanoSEM 650. Thermogravimetric analysis (TGA) of L/CNT coating samples and cotton roving composites was performed using TGA 4000, PerkinElmer apparatus. The measurement was performed with heating rate of $10{ }^{\circ} \mathrm{C} / \mathrm{min}$ in nitrogen atmosphere, and in the range of temperatures of $30-600{ }^{\circ} \mathrm{C}$.

Fire testing

\section{Mini fire tube}

The mini fire tube (MFT) method, was used for initial burning tests. MFT is an adopted and modified ASTM E69 technique(vertical burning in fire tube) (Grześkowiak 2017). Profile tube made of aluminium (length: $20 \mathrm{~mm} \times$ diameter: $20 \mathrm{~mm}$ ) is placed on the laboratory balance. The source of heat is a gas burner with adjustable flame height (preferred height is $1 \mathrm{~cm}$ ) mounted on a tripod. K-type thermocouple is used for the measurement of exhaust gases temperature at the outlet of the pipe. The experiment was performed using at least 10 samples (rod like shaped cotton roving samples: length-100 $\pm 1 \mathrm{~mm}$, diameter$16.9 \pm 1.5 \mathrm{~mm}$ and density of $31 \pm 5 \mathrm{mg} / \mathrm{cm}^{3}$ ) per each series (for the calculated saturation please see Supplementary Materials, Table S1).

After vertical burning test, sample residues were analyzed by Raman spectroscopy in order to investigate the presence of CNTs in samples after combustion. The Raman spectra were collected with a Jobin Horiba LabRAM HR 800 spectrometer connected to a CCD detector, in $1200-1800 \mathrm{~cm}^{-1}$ and

Table 1 The samples used for fire tests with their concentration in aqueous suspension

\begin{tabular}{lllllll}
\hline Sample & $\mathrm{C} / \mathrm{L}$ & $\mathrm{C} / \mathrm{L} / \mathrm{CNT}(0.05)$ & $\mathrm{C} / \mathrm{L} / \mathrm{CNT}(0.3)$ & $\mathrm{C} / \mathrm{L} / \mathrm{CNT}(1)$ & $\mathrm{C} / \mathrm{L}_{\mathrm{K}} \mathrm{CO}_{3}$ & $\mathrm{C} / \mathrm{L} / \mathrm{CNT}(1) / \mathrm{K}_{2} \mathrm{CO} \mathrm{CO}_{3}$ \\
\hline $\begin{array}{l}\text { Concentration in } \\
\text { aqueous }\end{array}$ & $1 \%$ lignin & $1 \%$ lignin & $1 \%$ lignin & $1 \%$ lignin & $1 \%$ lignin & $1 \%$ lignin \\
\begin{tabular}{l} 
suspension \\
\hline
\end{tabular} & & $0.05 \% \mathrm{CNTs}$ & $0.3 \% \mathrm{CNTs}$ & $1 \% \mathrm{CNTs}$ & $1 \% \mathrm{~K}_{2} \mathrm{CO}_{3}$ & $1 \% \mathrm{CNTs}$ \\
\end{tabular}


$2400-2800 \mathrm{~cm}^{-1}$ range. He-Ne laser excitation line of $633 \mathrm{~nm}$ was used for all experiments.

\section{Limiting oxygen index}

Limiting oxygen index (LOI) test is used to investigate the minimum amount of oxygen needed to maintain combustion. In order to estimate LOI, the concentration of oxygen was adjusted for each sample (in the mixture of oxygen and nitrogen), to maintain burning of the sample. Measurement was performed according to ISO 4589-1 standard and the samples were of the same size as for MFT method (for the calculated saturation please see Supplementary Materials, Table S2).

\section{Mass loss calorimeter}

Tests using mass loss calorimeter (MLC) were performed in accordance with ISO 13927 standard with a radiant heat of $25 \mathrm{~kW} / \mathrm{m}^{2}$. The applied radiant heat corresponds to the intensity of a heat flux in a small scale fire (Schartel et al. 2005). In each MLC test three cotton samples of $100 \times 100 \mathrm{~mm}$ (length $\times$ width) and $3.9 \pm 0.3 \mathrm{~mm}$ (thickness) were used. The initial mass, thickness and saturation of each sample is specified in Supplementary Materials (Fig. S3).MLC enables the measurement of heat release rate (HRR) as a function of time, peak heat release rate (PHRR), total heat released (THR), mean effective heat of combustion (EHC), time to ignition (TTI), time to flameout (TTF) and time to reach PHRR (TT PHRR). Due to low mass of cotton and balance accuracy, it was not possible to estimate mass loss rate of the samples.

\section{Results and discussion}

Initial characterization of lignin/carbon nanotube composites

Lignin, CNTs and L/CNT were dispersed according to the procedure described in "Cotton/lignin preparation" section and dried. Next, their decomposition was analyzed based on thermogravimetric (TG) and TG derivative (DTG) curves. CNTs (Fig. 1a, b) composed of $\mathrm{sp}^{2}$ bond carbon atoms are thermally stable up to approx. $500{ }^{\circ} \mathrm{C}$. On the other hand, lignin decomposes over a large temperature range due to its complex chemical structure with various decomposition pathways. In general, its decomposition may be simplified to 3 stages (Brebu and Vasile 2010; Watkins et al. 2015). First, endothermal process related to evaporation of residual water takes place in temperature range of $30-120{ }^{\circ} \mathrm{C}$ (DTG peak at $65{ }^{\circ} \mathrm{C}$ ). According to Fig. 1a in the investigated lignin sample, moisture content amounted to $10 \mathrm{wt} \%$. The second stage, in the range of $180-300{ }^{\circ} \mathrm{C}$, is related to thermal degradation of carbohydrates in lignin structure. The carbohydrates are converted to acetic acid and non-condensable gases, mainly $\mathrm{CO}, \mathrm{CO}_{2}$ and $\mathrm{CH}_{4}$. The concentration of the latter ones gradually increases entering the $3 \mathrm{rd}$ stage. The third stage occurs between 300 and $500{ }^{\circ} \mathrm{C}$, with a clear DTG peak at $320{ }^{\circ} \mathrm{C}$. It is mainly related to thermal degradation of phenolics, alcohols and aldehyde acids. In this stage the largest amount of volatile gasses is released (Brebu and Vasile 2010; Watkins et al. 2015). Finally, at $600{ }^{\circ} \mathrm{C}$ $40 \%$ of lignin decomposes.

The presence of $5 \mathrm{wt} \%$ of CNTs in the dry lignin structure (obtained by drying of L/CNT(0.05) solution), causes slight increase in thermal stability. According to both TG and DTG curves, thermal decomposition in the second and the third stage is similar to pure lignin. However at $600{ }^{\circ} \mathrm{C}$ only $34 \mathrm{wt} \%$ of $\mathrm{L} / \mathrm{CNT}(0.05)$ decomposes which is a $6 \%$ decrease in comparison to pure lignin.

The most significant changes are observed for L/CNT(1) composite. Moisture content dropped to $3.5 \mathrm{wt} \%$, but more important changes are observed in second and third stage of lignin decomposition. DTG peak appeared at $320{ }^{\circ} \mathrm{C}$ for both $\mathrm{L} / \mathrm{CNT}(0.05)$ and L/CNT(1) composites, but DTG itself dropped from $2.3 \% / \mathrm{min}$ to $1.0 \% / \mathrm{min}$ for larger CNT content. However much more importantly, DTG curve of L/CNT(1) composite does not show decomposition peak at $360{ }^{\circ} \mathrm{C}$, which is responsible for releasing most flammable gasses. Finally, at $600{ }^{\circ} \mathrm{C}$ only $29 \%$ of L/CNT decomposes.

The initial TGA characterization was followed by electron microscopy. Figure 1c, d present SEM image of L/CNT(0.05) and L/CNT(1). The bundles of CNTs are present in both compositions and in both cases they are uniformly distributed in lignin matrix (for SEM image of lignin coating please see Supplementary Materials, Fig. S1). 

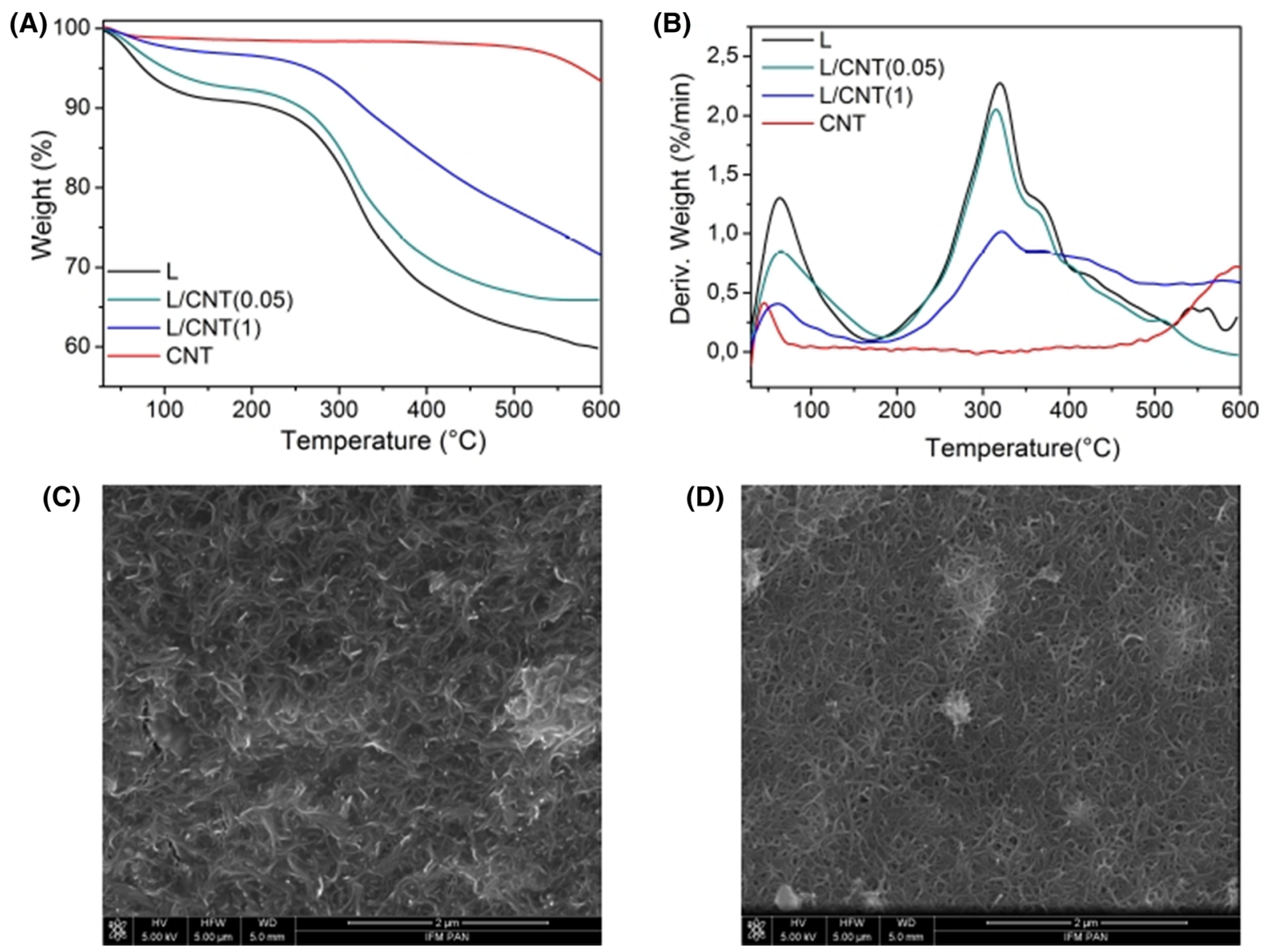

Fig. 1 TG (a) and DTG (b) curves of CNTs, L and L/CNT composites; SEM images of: c L/CNT(0.05) and d L/CNT(1)

Initial characterization of cotton coated by lignin/carbon nanotube dispersion

The initial TGA showed significant increase in thermal stability of lignin upon introduction of CNTs into its network. Therefore, further studies were performed. The cotton samples were coated with both lignin and various L/CNT composites according to "Cotton/lignin preparation" section. The obtained materials were further analyzed by several imaging methods. The camera and scanning electron microscope images of the cross-sectional areas of the samples showed that lignin coated mainly the lateral surface of the cotton sample but it is barely present inside cotton roving (Fig. 2a). This fact is not related to uneven distribution during deposition, but to the presence of capillary forces during drying. Upon drying lignin dissolved in water migrates to the outer parts of cotton roving, then it sets and forms a durable coating. Based on the latest research (Nishimura et al. 2018) it can be expected that lignin covalently bonds to cellulose by $\alpha$-ether bond between lignin and hydroxyl group of cellulose.

The phenomenon of coating of lateral surface is also observed for L/CNT(0.05) (Fig. 2b). However, as visible in Figs. 2c, d, the increase in the amount of CNTs in the L/CNT composites to $0.3 \%$ and $1 \%$, caused much better infiltration of both lignin and CNTs into the cotton samples. Particularly in case of L/CNT(1) cotton sample, it may be observed that lignin fills in the gaps between cotton fibers, while CNTs create a very dense network inside the cotton sample (Fig. 2d).

This observation may be explained firstly by the increase in viscosity of dispersion upon uniform dispersion of CNTs.. Moreover, the presence of high amount of CNTs caused stronger van der Waals interactions between cellulose and L/CNT network. 

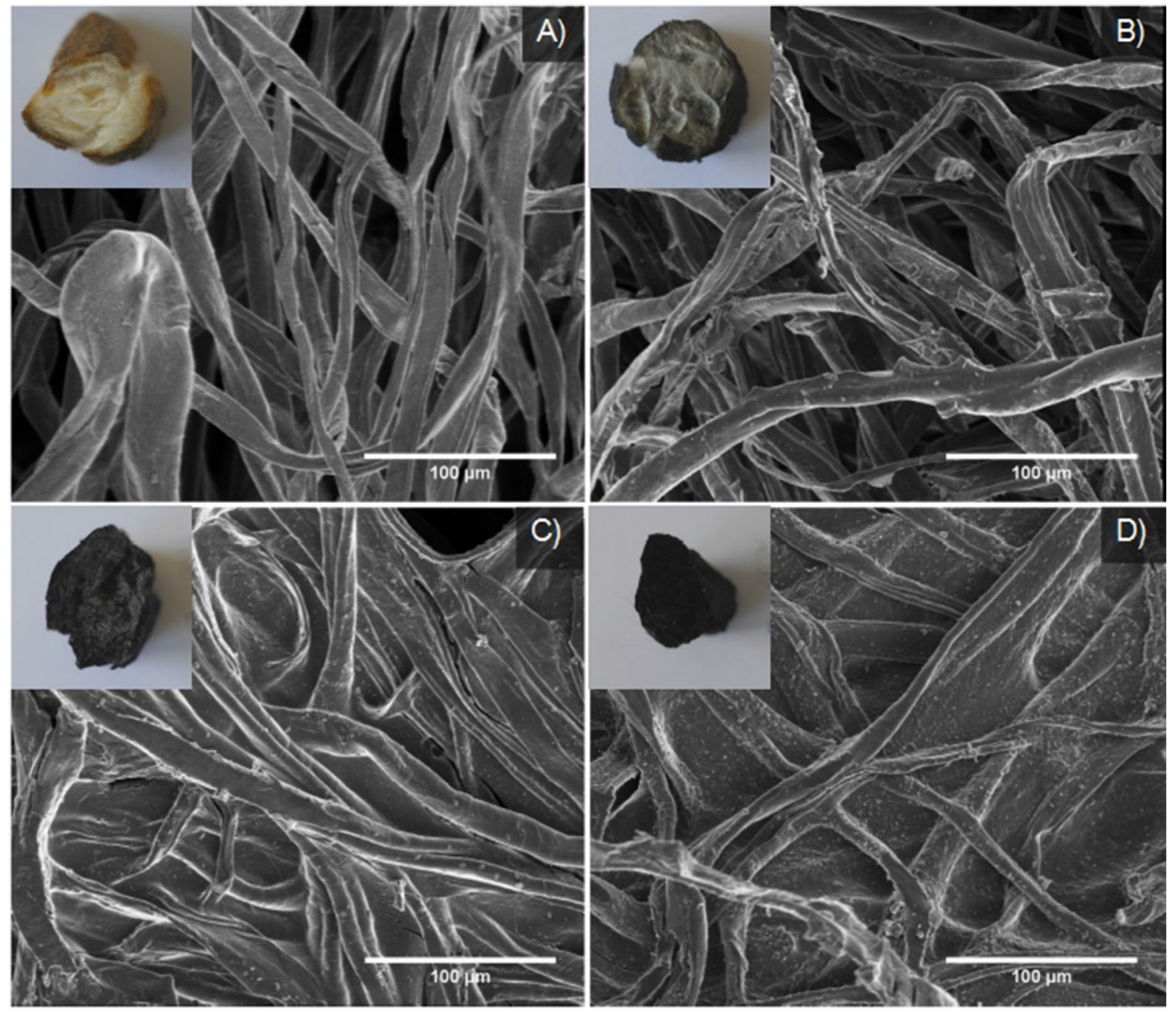

Fig. 2 SEM and camera (insert) images of: a C/L; b C/L/CNT(0.05); $\mathbf{c}$ C/L/CNT(0.3); d C/L/CNT(1)coated cotton samples

Both these phenomena are likely to cause significantly suppressed migration of components during drying and as a result deposition in the whole volume of the material.

Finally, in aqueous suspension CNTs are wrapped by lignin oligomers and interact with carbon rings by $\pi-\pi$ stacking (Perez and Martin 2015), this phenomenon causes an increase in lignin strength after mixing with CNTs, which is the reason for increased rigidity of the $\mathrm{C} / \mathrm{L} / \mathrm{CNT}$ samples.

The TG curve of cotton showed it rapid thermal decomposition starting at $275{ }^{\circ} \mathrm{C}$, with DTG peak at $370{ }^{\circ} \mathrm{C}$ (Fig. S2). Coating by $\mathrm{L}$ did not change the temperature of DTG peak, but significantly decreased the speed of decomposition. Even more, significant decrease in decomposition rate is observed for $\mathrm{C} / \mathrm{L} /$ CNT, probably due to more homogeneous distribution of coating onto cotton fibers (please see Supplementary Materials, Fig. S2). Both C/L/CNT and C/L/CNT/ $\mathrm{K}_{2} \mathrm{CO}_{3}$ showed shift in the temperature of DTG peak to $275^{\circ} \mathrm{C}$ and $269^{\circ} \mathrm{C}$, respectively. Additionally, they both showed significantly lower decomposition speed rate. The char residues at $600{ }^{\circ} \mathrm{C}$ increased gradually after applying each component, starting at $7.5 \%$ for cotton and ending with $28.8 \%$ for $\mathrm{C} / \mathrm{L} / \mathrm{CNT} / \mathrm{K}_{2} \mathrm{CO}_{3}$. 
Flammability

Fire tests were started from vertical burning in tube. In this experiment highest temperature of burning $\left(\mathrm{T}_{\max }\right)$, time to $\mathrm{T}_{\max }$ and mass loss were determined for pure cotton and coated cotton samples (Table 2). The pure cotton reached $\mathrm{T}_{\max }\left(457{ }^{\circ} \mathrm{C}\right)$ after $64 \mathrm{~s}$ and its final mass loss of $100 \%$. Coating of cotton with lignin $(\mathrm{C} / \mathrm{L})$, and $\mathrm{L} / \mathrm{CNT}$ dispersions with low CNT concentration i.e. $\mathrm{C} / \mathrm{L} / \mathrm{CNT}(0.05)$ and $\mathrm{C} / \mathrm{L} /$ $\mathrm{CNT}(0.3)$, caused significant decrease in $\mathrm{T}_{\max }$ and increase in time to $\mathrm{T}_{\max }$. However, no significant change in mass loss was noticed. The obtained results show that after coating of cotton with lignin and low concentration L/CNT composites, burning is significantly slower and takes place at lower temperature. However, due to no fire suppressing mechanism of these coatings, the samples decomposed completely.

Interestingly, the increase of CNT concentration to $1 \% \mathrm{C} / \mathrm{L} / \mathrm{CNT}(1)$ led to further decrease in $\mathrm{T}_{\max }$ and significant drop in mass loss to approx. 65\%, which indicates higher thermal stability of L/CNT coatings in comparison to pure cotton. Lower $\mathrm{T}_{\max }$ and mass loss are however, correlated with longer time to $\mathrm{T}_{\max }$, which is probably caused by two reasons. Firstly, decomposition of cotton in $\mathrm{C} / \mathrm{L} / \mathrm{CNT}(1)$ is slower due to fire retardant effect of L/CNT(1). Secondly, because of the lack of fire suppressing mechanism, the temperature is constantly rising, instead of reaching maximum followed by its decrease.

For the latter reason, the coating of cotton with mixture of lignin and $\mathrm{K}_{2} \mathrm{CO}_{3}$ was also tested. C/L/ $\mathrm{K}_{2} \mathrm{CO}_{3}$ sample showed significantly shorter time to $\mathrm{T}_{\max }$ and the lowest $\mathrm{T}_{\max }$ amounting to $161{ }^{\circ} \mathrm{C}$, which is caused by fire suppressant effect of $\mathrm{K}_{2} \mathrm{CO}_{3}$. Finally, the combination of lignin, $1 \%$ of $\mathrm{CNT}$ and $\mathrm{K}_{2} \mathrm{CO}_{3}$ was also tested. C/L/CNT(1)/ $\mathrm{K}_{2} \mathrm{CO}_{3}$, showed lower $\mathrm{T}_{\max }$ than $\mathrm{C} / \mathrm{L}$, lower mass loss than $\mathrm{C} / \mathrm{L} / \mathrm{K}_{2} \mathrm{CO}_{3}$, and shorter time to $\mathrm{T}_{\max }$ than $\mathrm{C} / \mathrm{L} / \mathrm{CNT}(1)$.

After vertical burning test the residues of $\mathrm{C} / \mathrm{L}, \mathrm{C} / \mathrm{L} /$ $\mathrm{CNT}(1)$ and $\mathrm{C} / \mathrm{L} / \mathrm{CNT}(1) / \mathrm{K}_{2} \mathrm{CO}_{3}$ samples were investigated using Raman spectroscopy. This technique is commonly used to detect the presence of $\mathrm{sp}^{2}$ bonded carbon structures and enables their differentiation from other forms of carbon (Fig. 3). In the spectra four main bands related to the carbon allotropes are observed. $G$ band $\left(1590 \mathrm{~cm}^{-1}\right)$ is activated in $\mathrm{sp}^{2}$ carbon materials. It is due to the allowed phonon mode at the center of the Brillouin zone. The $\mathrm{D}\left(1350 \mathrm{~cm}^{-1}\right)$ and $\mathrm{D}^{\prime}\left(1615 \mathrm{~cm}^{-1}\right)$ become active in the presence of disorder. The $\mathrm{D}$ peak corresponds to the breathing modes of carbon hexagons. 2D $\left(2650 \mathrm{~cm}^{-1}\right)$ band originates from a second-order process (Dresselhaus et al. 2010; Inoue et al. 2017).

The Raman spectrum of combusted $\mathrm{C} / \mathrm{L}$ has a broad intense $\mathrm{D}$ band with maximum at $1337 \mathrm{~cm}^{-1}$, and $\mathrm{G}$ band-at $1596 \mathrm{~cm}^{-1}$. The ratio of integral intensities of $D$ and $G$ band $(\mathrm{I}(\mathrm{D}) / \mathrm{I}(\mathrm{G}))$ amounts to 0.91 . The shape of spectra (wide and composed of many internal bands) and band parameters are consistent with results of Inoue et al. obtained for charcoal (Inoue et al. 2017). In the spectrum of $\mathrm{C} / \mathrm{L} / \mathrm{CNT}$ (1) following bands are observed: D $\left(1330 \mathrm{~cm}^{-1}\right), \quad \mathrm{G}\left(1584 \mathrm{~cm}^{-1}\right), \mathrm{D}^{\prime}$ $\left(1615 \mathrm{~cm}^{-1}\right)$ and 2D $\left(2650 \mathrm{~cm}^{-1}\right)$. D and $\mathrm{D}^{\prime}$ bands are observed due to the presence of defected CNTs (Dresselhaus et al. 2010). The same bands with higher noise signal ratio are observed for $\mathrm{C} / \mathrm{L} / \mathrm{CNT} / \mathrm{K}_{2} \mathrm{CO}_{3}$ sample residues. This may indicate that smaller amount of CNTs is present on the surface of the $\mathrm{C} / \mathrm{L} / \mathrm{CNT} / \mathrm{K}_{2} \mathrm{CO}_{3}$ sample, than on $\mathrm{C} / \mathrm{L} / \mathrm{CNT}$ samples. Upon burning $\mathrm{K}_{2} \mathrm{CO}_{3}$ creates highly porous char (Grzeskowiak 2012) and CNTs may be hidden inside of it.

Next, LOI indicating the minimum amount of oxygen in atmosphere needed to maintain ignition was
Table 2 Key flammability parameters obtained from MFT tests performed on pure cotton and cotton modified by various composite coatings

\begin{tabular}{lclc}
\hline Sample & Mass loss $(\%)$ & $\mathrm{T}_{\max }\left({ }^{\circ} \mathrm{C}\right)$ & Time to $\mathrm{T}_{\max }(\mathrm{s})$ \\
\hline $\mathrm{C}$ & $100 \pm 1$ & $457 \pm 15$ & $64 \pm 13$ \\
$\mathrm{C} / \mathrm{L}$ & $97 \pm 2$ & $210 \pm 15$ & $120 \pm 18$ \\
$\mathrm{C} / \mathrm{L} / \mathrm{CNT}(0.05)$ & $98 \pm 1$ & $185 \pm 9$ & $150 \pm 13$ \\
$\mathrm{C} / \mathrm{L} / \mathrm{CNT}(0.3)$ & $95 \pm 1$ & $184 \pm 10$ & $161 \pm 22$ \\
$\mathrm{C} / \mathrm{L} / \mathrm{CNT}(1)$ & $66 \pm 5$ & $174 \pm 11$ & $202 \pm 14$ \\
$\mathrm{C} / \mathrm{L} / \mathrm{K}_{2} \mathrm{CO}_{3}$ & $89 \pm 1$ & $161 \pm 8$ & $115 \pm 11$ \\
$\mathrm{C} / \mathrm{L} / \mathrm{CNT}(1) / \mathrm{K}_{2} \mathrm{CO}_{3}$ & $78 \pm 1$ & $190 \pm 8$ & $162 \pm 11$ \\
\hline
\end{tabular}




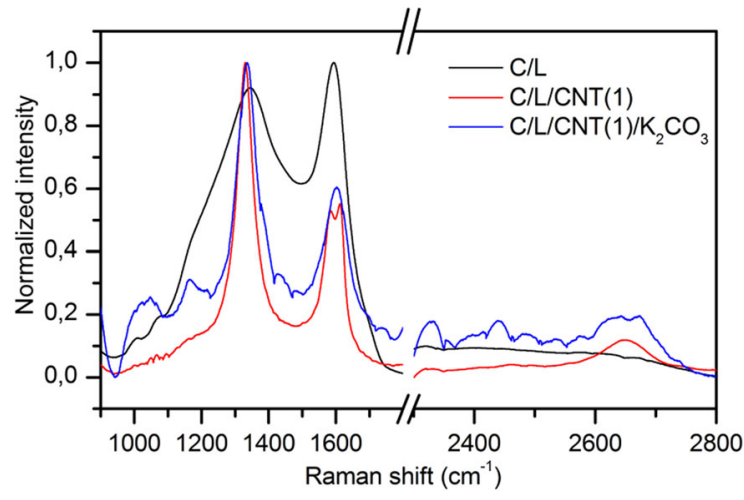

Fig. 3 Raman spectra of C/L, C/L/CNT(1) and C/L/CNT(1)/ $\mathrm{K}_{2} \mathrm{CO}_{3}$ sample residues obtained from vertical burning test

investigated (Table 3). Raw cotton sample showed LOI of $17.1 \%$. Pure lignin coating increased this parameter significantly to $26.8 \%$. This is because lignin exhibits better char formation capability than cotton and creates a protective barrier between volatile gasses released during combustion and oxygen. Similarly, to MFT test, only a slight improvement in flame retardant property was observed after addition of small amounts of CNTs i.e. for C/L/CNT(0.05) and C/L/ $\mathrm{CNT}(0.3)$. However, using dispersion with higher concentration of CNTs resulted in a much more significant fire retardant effect with LOI reaching $31.7 \%$ for C/L/CNT(1). This increase in LOI may be explained by two effects. Firstly, CNTs form network mechanically enhancing lignin-char gas barrier formation. Secondly, CNTs can accelerate charring of lignin due to high thermal conductivity. Possibly, both effects take place simultaneously. Increase in LOI was observed also after coating of cotton of with $\mathrm{L} / \mathrm{K}_{2} \mathrm{CO}_{3}$. This is due to natural flame suppressing effect of $\mathrm{K}_{2} \mathrm{CO}_{3}$ (Grzeskowiak 2012). The highest LOI was

Table 3 Limiting oxygen index of investigated samples

\begin{tabular}{ll}
\hline Sample & LOI (\%) \\
\hline $\mathrm{C}$ & 17.1 \\
$\mathrm{C} / \mathrm{L}$ & 26.8 \\
$\mathrm{C} / \mathrm{L} / \mathrm{CNT}(0.05)$ & 25.0 \\
$\mathrm{C} / \mathrm{L} / \mathrm{CNT}(0.3)$ & 27.5 \\
$\mathrm{C} / \mathrm{L} / \mathrm{CNT}(1)$ & 31.7 \\
$\mathrm{C} / \mathrm{L} / \mathrm{K}_{2} \mathrm{CO}_{3}$ & 32.5 \\
$\mathrm{C} / \mathrm{L} / \mathrm{CNT}(1) / \mathrm{K}_{2} \mathrm{CO}_{3}$ & 38.5 \\
\hline
\end{tabular}

observed for $\mathrm{C} / \mathrm{L} / \mathrm{CNT}(1) / \mathrm{K}_{2} \mathrm{CO}_{3}$ sample and reached $38.5 \%$ which is over 20 p.p. higher than for raw cotton.

The least flammable $\mathrm{C} / \mathrm{L} / \mathrm{K}_{2} \mathrm{CO}_{3}, \mathrm{C} / \mathrm{L} / \mathrm{CNT}(1)$ and $\mathrm{C} / \mathrm{L} / \mathrm{CNT}(1) / \mathrm{K}_{2} \mathrm{CO}_{3}$ samples were investigated further by mass loss calorimeter (MLC). $\mathrm{C}$ and $\mathrm{C} / \mathrm{L}$ samples were also tested as reference samples (Fig. 4). All samples ignited 8-16 s after application of a spark (for TTI and TTF please see Supplementary Materials, Table S4). The main parameters of burning in MLC test, such as PHRR, EHC and THR are presented in Table 4. It is clear that the highest PHRR, THR and EHC were measured for raw cotton, which amounted to $97.5 \mathrm{~kW} / \mathrm{m}^{2}$ and $4.2 \mathrm{~mJ} / \mathrm{m}^{2}$ and $15.7 \mathrm{MJ} / \mathrm{kg}$ respectively. C/L showed lower PHRR, THR and EHC values. Higher drop in flammability was observed for C/L/CNT(1), which THR and EHC dropped to $1.9 \mathrm{MJ} / \mathrm{m}^{2}$ and $7.2 \mathrm{MJ} / \mathrm{kg}$.

Significantly better flame suppressing properties were observed for all samples containing $\mathrm{K}_{2} \mathrm{CO}_{3}$, which PHRR varied from 63.1 to $70.4 \mathrm{~kW} / \mathrm{m}^{2}$. The difference between PHRR of $\mathrm{C} / \mathrm{L} / \mathrm{K}_{2} \mathrm{CO}_{3}$ and $\mathrm{C} / \mathrm{L} /$ $\mathrm{CNT}(1) / \mathrm{K}_{2} \mathrm{CO}_{3}$ is probably caused by slightly lower thickness and higher mass of $\mathrm{C} / \mathrm{L} / \mathrm{CNT}(1) / \mathrm{K}_{2} \mathrm{CO}_{3}$ (please see Supplementary Materials, Fig. S3). The lowest THR and EHC was measured for samples containing either CNTs or $\mathrm{K}_{2} \mathrm{CO}_{3}$. Additionally, $\mathrm{C} / \mathrm{L} /$ $\mathrm{CNT}(1) / \mathrm{K}_{2} \mathrm{CO}_{3}$ shows the lowest time to reach PHRR (30 s), which corresponds to the highest charring rate.

Discussion on flame retardation mechanism

Process of burning of cellulose-based cotton fibers can be divided into two stages. First, the degradation of

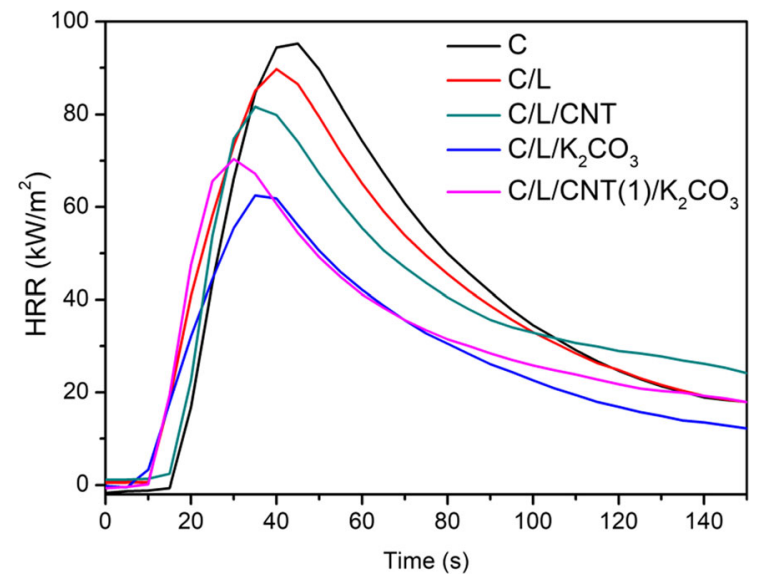

Fig. 4 Heat release rate (HRR) recorded during MLC test 
Table 4 Key flammability parameters obtained from mass loss calorimeter test (radiant heat of $25 \mathrm{~kW} / \mathrm{m}^{2}$ ) obtained for cotton and cotton modified by various composite coatings

\begin{tabular}{lllll}
\hline Sample & PHRR $\left(\mathrm{kW} / \mathrm{m}^{2}\right)$ & THR $\left(\mathrm{MJ} / \mathrm{m}^{2}\right)$ & EHC $(\mathrm{MJ} / \mathrm{kg})$ & TT PHRR $(\mathrm{s})$ \\
\hline $\mathrm{C}$ & $97.5 \pm 4.7$ & $4.2 \pm 0.4$ & $15.7 \pm 3.8$ & $42 \pm 5$ \\
$\mathrm{C} / \mathrm{L}$ & $89.8 \pm 0.2$ & $3.2 \pm 0.3$ & $8.7 \pm 0.7$ & $38 \pm 5$ \\
$\mathrm{C} / \mathrm{L} / \mathrm{CNT}(1)$ & $81.6 \pm 3.1$ & $1.9 \pm 0.5$ & $7.2 \pm 1.4$ & $35 \pm 5$ \\
$\mathrm{C} / \mathrm{L} / \mathrm{K}_{2} \mathrm{CO}_{3}$ & $63.1 \pm 3.2$ & $1.4 \pm 0.1$ & $7.5 \pm 1.1$ & $38 \pm 5$ \\
$\mathrm{C} / \mathrm{L} / \mathrm{CNT}(1) / \mathrm{K}_{2} \mathrm{CO}_{3}$ & $70.4 \pm 2.5$ & $1.6 \pm 0.4$ & $7.3 \pm 0.8$ & $30 \pm 5$ \\
\hline
\end{tabular}

cellulose leads to the formation of char, tars as well as flammable and non-flammable gases. The second phase of cotton burning is caused by oxidation of the flammable gases in high temperature. Due to very rapid decomposition of cellulose fibers the amount of char produced in the whole process is insignificant (Horrocks 1983). According to flammability tests, maximum temperature of fumes during vertical burning $\left(\mathrm{T}_{\max }\right)$ of raw cotton amounts to $457^{\circ} \mathrm{C}$, LOI- $17.1 \%$ and PHRR-97.5 kW/m².

On the contrary, lignin slowly decomposes and leaves a significant amount of char (Brebu and Vasile 2010; Watkins et al. 2015), which forms a natural barrier for flammable gases. The above presented results clearly indicate, that even a thin coating layer of lignin on cotton is sufficient to have a significant flame retardant effect, as a result of increased char formation. Lignin coated samples showed a decrease in $\mathrm{T}_{\max }$ (MFT test) and PHRR (MLC test) to $210{ }^{\circ} \mathrm{C}$ and $89.8 \mathrm{~kW} / \mathrm{m}^{2}$, respectively, and an increase in LOI to $26.8 \%$. Analysis of sample cross-section images (Fig. 2a) shows, however, that lignin deposits only as a shell on the cotton fibers. It may be expected that its more uniform volumetric distribution could increase fire retardant properties.

In previous studies (Kashiwagi et al. 2005a, b; Cipiriano et al. 2007), describing flame retardant effect of CNTs on polymers, the CNTs were described as responsible for accelerating char formation, char strengthening and reduction of polymer bubbling during decomposition. The presented above study showed that addition of CNTs may influence both thermal stability of lignin (Fig. 1a, b) and better adhesion of lignin to cellulose fibers within the whole volume (Fig. 2c, d), which, in consequence, leads to further enhancement of fire retardant effect. The partial thermal resistance was observed for $\mathrm{C} / \mathrm{L} /$
CNT(1) with $\mathrm{T}_{\max }-174{ }^{\circ} \mathrm{C}, \quad$ LOI-32.0\% and PHRR $-81.6 \mathrm{~kW} / \mathrm{m}^{2}$. A significant improvement, especially in $\mathrm{T}_{\max }$ and LOI, may be caused by several factors. First of all, more uniform volumetric distribution of L/CNT(1) in comparison to pure lignin causes not only surface but also volumetric protection (Fig. 2d). Secondly, CNTs are thermally stable to over $500{ }^{\circ} \mathrm{C}$ and may mechanically stabilize the ligninorigin char, which is proved by presence of CNTs in C/L/CNT(1) after vertical burning (Fig. 3). Thirdly, CNTs enriched char may also constitute a better gas barrier which is particularly important for LOI.

The other approach to decrease flammability of $\mathrm{C} / \mathrm{L}$ was using $\mathrm{K}_{2} \mathrm{CO}_{3}$, which dilutes cotton-origin flammable gases, by releasing non-flammable $\mathrm{CO}_{2}$ during high temperature decomposition. This mechanism may be indicated as responsible for not observed in $\mathrm{C} / \mathrm{L}$ and $\mathrm{C} / \mathrm{L} / \mathrm{CNT}(1)$ samples decrease in PHRR to $63.1 \mathrm{~kW} / \mathrm{m}^{2}$. The improvement with regard to pure $\mathrm{C} / \mathrm{L}$ was also observed in $\mathrm{T}_{\max }$ and $\mathrm{LOI}$, which amounted to $161{ }^{\circ} \mathrm{C}$ and $32.5 \%$, respectively.

The synergistic action of lignin, CNTs and $\mathrm{K}_{2} \mathrm{CO}_{3}$ caused the most significant reduction of flammability of cotton fibers. $\mathrm{C} / \mathrm{L} / \mathrm{CNT}(1) / \mathrm{K}_{2} \mathrm{CO}_{3}$ showed $\mathrm{T}_{\max }-$ $190{ }^{\circ} \mathrm{C}, \quad$ LOI- $38.5 \%$, PHRR-70.4 kW/m ${ }^{2}$ and EHC-7.3 MJ/kg. In detail, PHRR, THR and EHC values of $\mathrm{C} / \mathrm{L} / \mathrm{CNT}(1) / \mathrm{K}_{2} \mathrm{CO}_{3}$ are significantly lower than those of $\mathrm{C} / \mathrm{L} / \mathrm{CNT}$ and similar to $\mathrm{C} / \mathrm{L} / \mathrm{K}_{2} \mathrm{CO}_{3}$. Simultaneously, LOI of $\mathrm{C} / \mathrm{L} / \mathrm{CNT}(1) / \mathrm{K}_{2} \mathrm{CO}_{3}$ is much higher than for the other samples. This indicates improvement in characteristic parameters of a set of experiments performed normally to investigate fire retardancy of materials including TGA, vertical burning, LOI and MLC and not just a single one.

In this composite CNT reinforced lignin network is responsible for effective formation of mechanically stable char which creates gas barrier between oxygen 
and flammable gases, increasing LOI and decreasing $\mathrm{T}_{\text {max }}$. This means that $\mathrm{L} / \mathrm{CNT}(1)$ coating is responsible for inhibiting of fire at an early stage of burning. On the contrary, $\mathrm{K}_{2} \mathrm{CO}_{3}$ caused dilution of flammable gases, causing extinguishing of fire at the later stage. Thus the synergetic effect of lignin, CNTs and $\mathrm{K}_{2} \mathrm{CO}_{3}$ enabled the decrease in flammability using compatible mechanisms.

\section{Conclusions}

In this study a fire retardant composite coating of cotton fibers has been proposed. The flammability tests including TGA, MFT, LOI, MLC as well as SEM and Raman spectroscopy enables the formulation of the optimum composition of the coating including $1 \mathrm{wt} \%$ lignin, $1 \mathrm{wt} \%$ of CNTs and $1 \mathrm{wt} \%$ of potassium carbonate. The mechanisms responsible for the overall fire-retardant effect were also explained.

Briefly, lignin due to high char formation ability is a natural flame retardant agent. The formed char constitutes a gas barrier for the flammable gases and oxygen slowing down the burning process. The addition of CNTs accelerates the char formation and strengthens its structure. Moreover, carbon nanotube additives cause more uniform lignin distribution in cellulose matrix. The above compounds, are effective during early-stage of burning. On the other hand, $\mathrm{K}_{2} \mathrm{CO}_{3}$ dilutes flammable gases at the later stage during thermal decomposition. Overall, the fire retardant properties of the proposed coatings are a composition of passive fire retardant action of L/CNTs coating causing higher LOI and slower vertical burning, and $\mathrm{K}_{2} \mathrm{CO}_{3}$ action relying on dilution of flammable gases at high temperatures.

Acknowledgments D. Ł. would like to thank the National Science Centre, Poland (Project No. 2015/19/N/ST8/02184) and A. D. the Ministry of Higher Education, Poland, for sponsoring the study.

Open Access This article is licensed under a Creative Commons Attribution 4.0 International License, which permits use, sharing, adaptation, distribution and reproduction in any medium or format, as long as you give appropriate credit to the original author(s) and the source, provide a link to the Creative Commons licence, and indicate if changes were made. The images or other third party material in this article are included in the article's Creative Commons licence, unless indicated otherwise in a credit line to the material. If material is not included in the article's Creative Commons licence and your intended use is not permitted by statutory regulation or exceeds the permitted use, you will need to obtain permission directly from the copyright holder. To view a copy of this licence, visit http://creativecommons.org/licenses/by/4.0/.

\section{References}

Bocchini S, Camino G, Joseph P, Ebdon JR (2010) Fire retardants of polymeric materials, 2nd edn. Taylor \& Francis, Boca Raton

Brebu M, Vasile C (2010) Thermal degradation of lignin-a review. Cellul Chem Technol Cellul Chem Technol 44:353-363

Chen X, Fang F, Zhang X et al (2016) Flame-retardant, electrically conductive and antimicrobial multifunctional coating on cotton fabric via layer-by-layer assembly technique. RSC Adv 6:27669-27676. https://doi.org/10. 1039/c5ra26914h

Cipiriano BH, Kashiwagi T, Raghavan SR et al (2007) Effects of aspect ratio of MWNT on the flammability properties of polymer nanocomposites. Polymer 48:6086-6096. https:// doi.org/10.1016/j.polymer.2007.07.070

Ding X, Fang F, Du T et al (2016) Carbon nanotube-filled intumescent multilayer nanocoating on cotton fabric for enhancing flame retardant property. Surf Coat Technol 305:184-191. https://doi.org/10.1016/j.surfcoat.2016.08. 035

Dresselhaus MS, Jorio A, Souza Filho AG, Saito R (2010) Defect characterization in graphene and carbon nanotubes using Raman spectroscopy. Philos Trans R Soc A Math Phys Eng Sci 368:5355-5377. https://doi.org/10.1098/rsta. 2010.0213

Gaan S, Sun G (2009) Effect of nitrogen additives on thermal decomposition of cotton. J Anal Appl Pyrolysis 84:108-115. https://doi.org/10.1016/j.jaap.2008.12.004

Gonçalves AG, Jarrais B, Pereira C et al (2012) Functionalization of textiles with multi-walled carbon nanotubes by a novel dyeing-like process. J Mater Sci 47:5263-5275. https://doi.org/10.1007/s10853-012-6412-4

Grzeskowiak W (2012) Evaluation of the effectiveness of the fire retardant mixture containing potassium carbonate using a cone calorimeter Wojciech. Fire Mater 36:75-83. https://doi.org/10.1002/fam.1088

Grześkowiak W (2017) Effectiveness of new wood fire retardants using a cone calorimeter. J Fire Sci 35:565-576. https://doi.org/10.1177/0734904117737464

Horrocks AR (1983) An introduction to the burning behaviour of cellulosic fibres. J Soc Dye Colour 99:191-197. https:// doi.org/10.1111/j.1478-4408.1983.tb03686.x

Inoue J, Yoshie A, Tanaka T et al (2017) Disappearance and alteration process of charcoal fragments in cumulative soils studied using Raman spectroscopy. Geoderma 285:164-172. https://doi.org/10.1016/j.geoderma.2016.09. 032

Kandola BK, Horrocks AR, Price D, Coleman GV (1996) Flame-retardant treatments of cellulose and their influence on the mechanism of cellulose pyrolysis. J Macromol Sci Part C Polym Rev 36(4):721-794 
Kashiwagi T, Du F, Douglas JF et al (2005a) Nanoparticle networks reduce the flammability of polymer nanocomposites. Nat Mater 4:928-933. https://doi.org/10.1038/ nmat 1502

Kashiwagi T, Du F, Winey KI et al (2005b) Flammability properties of polymer nanocomposites with single-walled carbon nanotubes: effects of nanotube dispersion and concentration. Polymer 46:471-481. https://doi.org/10. 1016/j.polymer.2004.10.087

Lee JH, Yu IJ (2017) Human exposure to polyhexamethylene guanidine phosphate from humidifiers in residential settings: cause of serious lung disease. Toxicol Ind Health 33:835-842. https://doi.org/10.1177/0748233717724983

Łukawski D, Lekawa-Raus A, Lisiecki F et al (2018a) Towards the development of superhydrophobic carbon nanomaterial coatings on wood. Prog Org Coat 125:23-31. https://doi. org/10.1016/j.porgcoat.2018.08.025

Łukawski D, Lisiecki F, Dudkowiak A (2018b) Coating cellulosic materials with graphene for selective absorption of oils and organic solvents from water. Fibers Polym 19:524-530. https://doi.org/10.1007/s12221-018-7879-7

Łukawski D, Grześkowiak W, Mazela B et al (2019) The influence of surface modification of wood particles with carbon nanotubes on properties of particleboard glued with phenyl-formaldehyde resin. Drewno 62:93-105. https:// doi.org/10.12841/wood.1644-3985.265.03

Lyche JL, Rosseland C, Berge G, Polder A (2015) Human health risk associated with brominated flame-retardants (BFRs). Environ Int 74:170-180. https://doi.org/10.1016/j.envint. 2014.09.006

Lyons J (1976) Flame-retardant polymeric materials. In: Lewin M, Atlas SM, Pearce EM (eds) Plenum Press, New York, 1975. J Polym Sci Polym Lett Ed 14:569-570. https://doi. org/10.1002/pol.1976.130140912

Milczarek G, Nowicki M (2013) Carbon nanotubes/kraft lignin composite: characterization and charge storage properties. Mater Res Bull 48:4032-4038. https://doi.org/10.1016/j. materresbull.2013.06.022

Mohamed AL, Hassabo AG (2015) Flame retardant of cellulosic materials and their composites. In: Visakh PM, Arao Y (eds) Flame retardants, 1st edn. Springer, Switzerland, pp 247-314

Nishimura H, Kamiya A, Nagata T et al (2018) Direct evidence for $\alpha$ ether linkage between lignin and carbohydrates in wood cell walls. Sci Rep 8:1-11. https://doi.org/10.1038/ s41598-018-24328-9

Perez E, Martin N (2015) $\pi-\pi$ interactions in carbon nanostructures. Chem Soc Rev 44:6425-6433. https://doi.org/10. 1039/c5cs00578g

Rahman F, Langford KH, Scrimshaw MD, Lester JN (2001) Polybrominated diphenyl ether (PBDE) flame retardants. Sci Total Environ 275:1-17. https://doi.org/10.1016/ s0048-9697(01)00852-x

Reti C, Casetta M, Dequesne S et al (2008) Flammability properties of intumescent PLA including starch and lignin. Polym Adv Technol Polym 19:628-635. https://doi.org/10. 1002/pat.1130

Schartel B, Bartholmai M, Knoll U (2005) Some comments on the use of cone calorimeter data. Polym Degrad Stab 88:540-547. https://doi.org/10.1016/j.polymdegradstab. 2004.12.016

Shen DK, Gu S (2009) The mechanism for thermal decomposition of cellulose and its main products. Bioresour Technol 100:6496-6504. https://doi.org/10.1016/j.biortech.2009. 06.095

Shen D, Xiao R, Gu S, Luo K (2011) The pyrolytic behavior of cellulose in lignocellulosic biomass: a review. RSC Adv 1:1641-1660. https://doi.org/10.1039/c1ra00534k

Song P, Cao Z, Fu S et al (2011) Thermal degradation and flame retardancy properties of ABS/lignin: effects of lignin content and reactive compatibilization. Thermochim Acta 518:59-65. https://doi.org/10.1016/j.tca.2011.02.007

Vänskä E, Vihelä T, Peresin MS et al (2016) Residual lignin inhibits thermal degradation of cellulosic fiber sheets. Cellulose 23:199-212. https://doi.org/10.1007/s10570015-0791-z

Vroman I, Tighzert L (2009) Biodegradable polymers. Materials 2:307-344. https://doi.org/10.3390/ma2020307

Watkins D, Nuruddin M, Hosur M et al (2015) Extraction and characterization of lignin from different biomass resources. J Mater Res Technol 4:26-32. https://doi.org/10.1016/j. jmrt.2014.10.009

White RH, Nordheim EV (1992) Charring rate of wood for ASTM E 119 exposure. Fire Technol 28:5-30

Publisher's Note Springer Nature remains neutral with regard to jurisdictional claims in published maps and institutional affiliations. 